\title{
Da etnografia ao indigenismo: uma trajetória antropológica
}

\section{Alcida Rita Ramos}

\section{(2) OpenEdition \\ 1 Journals}

Edição electrónica

URL: http://journals.openedition.org/aa/773

DOI: $10.4000 /$ aa. 773

ISSN: 2357-738X

\section{Editora}

Programa de Pós-Graduação em Antropologia Social (UnB)

\section{Edição impressa}

Data de publição: 1 junho 2010

Paginação: 43-56

ISSN: 0102-4302

\section{Refêrencia eletrónica}

Alcida Rita Ramos, «Da etnografia ao indigenismo: uma trajetória antropológica», Anuário

Antropológico [Online], v.35 n. 1 | 2010, posto online no dia 07 outubro 2015, consultado o 28 abril

2021. URL: http://journals.openedition.org/aa/773 ; DOI: https://doi.org/10.4000/aa.773

\section{(c) $)(1)$}

Anuário Antropológico is licensed under a Creative Commons Atribuição-Uso Não-Comercial-Proibição de realização de Obras Derivadas 4.0 International. 


\title{
Da etnografia ao indigenismo: uma trajetória antropológica*
}

\author{
Alcida Rita Ramos \\ Departamento de Antropologia / UnB
}

Por que alguém escolhe ser antropólogo? Já me fiz esta pergunta muitas vezes e a faço periodicamente aos estudantes de pós-graduação. Será uma atração fatal que a disciplina exerce sobre um certo tipo de pessoas, será uma inapetência por outras profissões, ou uma combinação das duas coisas? Invariavelmente, as respostas que tenho obtido têm sempre um denominador comum: alguma coisa na história de vida das pessoas empurra-as para o que é inusitado, surpreendente. Tenho chamado essa "coisa" de descompasso, uma sensação quase sempre difusa de que eu e o meu meio social não estamos exatamente em harmonia, seja por efeito de uma migração, de uma experiência familiar dolorosa ou mal resolvida, ou da exposição a situações incômodas e até contraditórias. Em outras palavras, é uma insatisfação quase subliminar, subjacente à vida que vivemos de maneira aparentemente "normal". É interessante notar que a própria sociedade que gera esse mal-estar também fornece saídas - umas mais honrosas que outras - com alternativas de acomodação aos portadores desses descompassos. Vem-me à lembrança a instituição indígena da berdache, pela qual os homens das sociedades guerreiras das planícies norte-americanas, sem vocação para a guerra, podiam legitimamente optar por assumir papéis femininos. Vestiam-se como mulheres, desempenhavam tarefas de mulheres e essa opção era plenamente respeitada e acatada por seus pares.

A exemplo desses índios, podemos dizer que, também entre nós, as pessoas que fogem aos cânones profissionais de uma sociedade industrial inclinada à produtividade econômica dispõem de alguns canais legítimos de expressão, como os vários caminhos abertos para as artes. Quero crer que a antropologia entra nesse nicho. Por alguma razão que não é difícil vislumbrar, o fazer antropológico combina com quem procura satisfação existencial fora das expectativas consagradas pelo mundo ocidental. Parafraseando Michel-Rolph Trouillot (1991) quando afirma que a antropologia ocupou o savage slot ("nicho selvagem") no escaninho das ciências humanas há dois ou três séculos atrás, vale a pena aventar a ideia de que a antropologia preenche para muitos de nós o existential slot no escaninho das possibilidades que a sociedade nos dá para que o nosso Bildung ${ }^{1}$ seja construído.

Levanto tudo isto para começar a discorrer sobre a minha escolha pela etnologia 
indígena. Foi uma decisão instantânea, um caso de amor à primeira vista. Cursava eu geografia no que é hoje a Universidade Federal Fluminense e fazia uma disciplina de etnologia com o saudoso Professor Luis de Castro Faria. Encantava-me ouvir palavras de um vocabulário novo e deslumbrante: relativismo cultural, empatia, rapport... Fascinava-me ler sobre as experiências dos etnógrafos, por exemplo, a de Herbert Baldus sendo apalpado pelos índios Tapirapé que testavam a sua condição de ser humano. Aquele estranhamento amistoso de parte a parte - os índios assoando o nariz na camisa do etnógrafo... - parecia-me a quintessência da plenitude sensorial. De maneira mais subliminar do que consciente, percebi que vivências como aquelas, orientadas por uma boa dose de teoria e reflexão fenomenológica, poderiam produzir um novo compasso em minha vida. Eu queria entender melhor o meu mundo e encontrei na alegoria do antípoda "de casa" o caminho mais curto para chegar lá. Foi assim que a profissão de antropóloga aderiu à minha existência e passou a ser o meu horizonte de vida.

Mas todo esse fascínio precisava ser domesticado, disciplinado pelo estudo profundo e longo da antropologia. Meu treinamento, que obviamente continua até hoje, começou com um curso de especialização e, para o meu próprio espanto, já que não estava nos meus planos originais, acabou num diploma de doutorado nos Estados Unidos mais de dez anos depois. Fui primeiro aprender a ser uma scholar com o também saudoso Roberto Cardoso de Oliveira, que acabara de se transferir do Museu do Índio para o Museu Nacional no Rio de Janeiro. Cursando geografia na proto-UFF, eu partilhava as aulas de Castro Faria com Roberto DaMatta e sua futura mulher, Celeste, ambos alunos de história. Foi o extrovertido Matta que, talvez sem o saber, me incitou a estagiar no Museu Nacional, onde ele já estava há meses sendo treinado por RCO, como Cardoso de Oliveira passou a ser chamado por seus pupilos. Matta vinha para as aulas na UFF enchendo a boca com nomes pomposos e carregados de mistério tentador, como Radcliffe-Brown, Evans-Pritchard, Meyer Fortes, e sempre me deixava com a sensação de estar perdendo alguma coisa muito importante. Procurei RCO e me juntei ao Matta no estágio do Museu. Castro Faria, Matta e eu morávamos em Niterói, o que fazia das lentas travessias de barca, no ritmo Mississipi, um prolongamento nem sempre relaxado, mas, em retrospecto, muito divertido, daquelas longas horas de leitura e oralidade antropológicas que nos consumiam a semana inteira na Quinta da Boa Vista. Essas viagens rotineiras pela baía de Guanabara acabaram por gerar um saboroso folclore que agora pertence ao arquivo de memórias da nossa juventude.

Pouco depois, no início de 1960, RCO organizou seu primeiro curso de antropologia social no Museu, que incluiu uma viagem a campo entre os índios Terena urbanizados no Mato Grosso do Sul. Éramos seis alunos - incluídos aí Roberto 
DaMatta, Roque Laraia e eu - concentradíssimos em volta de uma longa mesa, separados do mestre por um fino tapume que não isolava as nossas conversas a meia-voz: nós estudávamos de cá, RCO lia e ouvia de lá, e não passava um dia sem que ele interrompesse sua leitura para vir nos corrigir alguma bobagem de neófitos. Um dia por semana ele dava uma aula expositiva. O resto da semana era leitura, leitura, leitura; troca de ideias, seminários, e mais leitura. Posso dizer que a minha formação antropológica foi feita ali, naquele recinto vetusto em meio aos aventais brancos da Ciência, cercado de crânios em estantes de vidro e o eterno cheiro de formol. Foi um ano de aprendizado árduo, intenso e sumamente gratificante, partilhado com colegas inesquecíveis e supervisionado de perto por um antropólogo jovem e ambicioso que, visto do aqui e agora, parecia plenamente seguro do papel central que viria a ter na história da antropologia brasileira. Tudo que me veio depois com o mestrado, o doutorado e a docência, como camadas geológicas, vieram assentar-se com naturalidade sobre o substrato sólido que adquiri no Museu Nacional do início dos anos 60.

Lá aprendi também a levar em consideração o aspecto político do fazer antropológico. Era a fase de construção do modelo da fricção interétnica e todos os meus colegas engajaram-se em pesquisas de relações interétnicas orientadas por um forte componente político. Coube-me, a contragosto, fazer meu trabalho de campo com um grupo urbano de pescadores portugueses no Rio de Janeiro, e minha experiência etnográfica com índios teve que esperar até o final da década de 60.

Quando fui para a Universidade de Wisconsin em 1962, estava imbuída do espírito crítico que reinava no Museu Nacional. Minha expectativa era trabalhar com algum povo sofrido pelas agruras do contato perverso com a sociedade dominante. Mas o terreno estadunidense não era fértil para coisas políticas. Não era sequer correto se falar de classes sociais, de modo que foi preciso temperar meu léxico na tese de mestrado sobre os pescadores portugueses com termos que não exigissem uma longa discussão conceitual capaz de convencer meus examinadores da utilidade de noções para eles altamente suspeitas.

Por razões mais pessoais do que profissionais, acabei por eleger para minha pesquisa de doutorado um povo indígena "isolado" (ainda se usavam termos como este na antropologia) como "objeto" (outro termo da fase ingênua pré-pós-moderna). Cheguei a me sentir um tanto culpada de vir ao Brasil fazer trabalho de campo “apolítico", com temas da antropologia anglo-saxã clássica, sem nenhum viés aparente de "consciência crítica", como qualquer aluno gringo em busca do nativo antes de ser perdido. Naquela época, os Yanomami nem eram conhecidos como Yanomami. Darcy Ribeiro referira-se vagamente a eles como waicás, outros os chamavam de guaharibo, outros de surara-pakidai, e ninguém sabia os limites territoriais, muito 
menos os linguísticos e culturais, daquela gente. Mas nem por isso eram considerados dignos de investimento etnográfico: eram isolados demais e tudo indicava que não sofriam de fricção interétnica.

Apesar das interrogações que me fizeram aqui no Brasil sobre aquela minha opção de pesquisa, desapareci por uns dois anos entre os Sanumá do rio Auaris disposta a pesquisar um assunto já tido como um tanto anacrônico: organização social. Caí no savage slot fora do tempo e do lugar certos. Mal sabíamos nós todos o que estava por vir vinte anos depois: o desatino da corrida do ouro em Roraima, o morticínio em massa de índios yanomami sob o efeito de repetidas pandemias de malária, a publicidade mundial sobre o escândalo de seu genocídio, a mobilização política a seu favor e o papel fundamental da pesquisa etnográfica clássica na defesa de seus direitos. Ao fim e ao cabo, não foi preciso inventar uma fricção interétnica para legitimar a minha escolha de campo etnográfico. Para consternação geral, o contato interétnico abateu-se sobre os Yanomami como uma onda gigante e mortífera. Se isso serve de consolo, ainda bem que houve tempo de elaborar um quadro etnográfico dos Yanomami antes da tragédia do garimpo, pois esse conhecimento foi instrumental para assegurar-lhes ao menos os seus direitos territoriais com a demarcação da Terra Indígena Yanomami (TIY) em 1991.

Os textos que Bruce Albert e eu elaboramos ao longo de mais de vinte anos de reivindicações por essa demarcação foram fundamentais para substanciar os argumentos em prol de uma área de tamanho tal que poupe aos Yanomami no futuro o destino de tantos outros povos indígenas que se veem às voltas com uma população crescente espremida em retalhos de terra indignos da condição humana, como é o caso, por exemplo, dos Guarani de Dourados.

Se a etnografia tradicional é tão grata e potencialmente útil, por que mudar de assunto? Por que troquei o campo indígena pela arena do indigenismo? Existem vários motivos para isso e talvez eu não tenha suficiente habilidade de autoanálise para mapear todos eles. No momento consigo identificar três desses motivos: um de ordem, digamos, existencial, outro de ordem propriamente acadêmica e o terceiro de ordem, por assim dizer, processual. Vou explicitar cada um deles, mas com a ressalva de que é apenas uma primeira tentativa de autocompreensão do meu lugar no mundo antropológico.

O fator da ordem que chamo existencial traz de volta a discussão da pesquisa politicamente relevante. Apesar de reconhecer que o meu trabalho de campo com os Sanumá nos moldes clássicos, ainda que de forma imprevista, veio a contribuir - e muito - para a argumentação em favor da demarcação da TIY, ficou-me a sensação de incompletude por não ter desenvolvido uma pesquisa inquestionavelmente de cunho político no campo das relações interétnicas. Naquele contexto de 
calmaria interétnica no noroeste de Roraima (1968-70), não havia porque embarcar numa pesquisa sobre relações de contato dos Sanumá com o mundo exterior, pois não havia muito que dizer além de constatar as repercussões dos missionários protestantes, assim mesmo de impacto limitado. Minha tentativa mais próxima disto foi a pesquisa de 1974 sobre relações intertribais, que resultou na coletânea Hierarquia e Simbiose (Ramos, 1980). Era uma época de grande tranquilidade para os Sanumá, tranquilidade esta que só pude aquilatar plenamente quase duas décadas depois, quando partilhei de sua aflição ante a catástrofe das invasões garimpeiras e as consequentes ondas intermináveis de malária.

No entanto, sempre senti que eu devia a mim mesma a experiência de exercer minha consciência crítica no campo da pesquisa antropológica. Aos poucos, quase sem sentir, fui me envolvendo com as vicissitudes de outros índios. Era a década de 80, o Brasil estava para sair da ditadura militar e o movimento indígena estava na sua fase heróica, em que brotavam líderes de grupos com longas e dramáticas experiências de contato interétnico desastroso e mal resolvido. Depois de um exílio voluntário de quase três anos na anódina Escócia, eu clamava por ação e até agitação. Fui anfitriã em Brasília de personagens marcantes, como o já falecido Paulinho Bororo, o ousado Álvaro Tukano, o empolgante Ailton Krenak, o diplomático Marcos Terena e o aparentemente franzino e plácido Tikuna, Pedro Inácio. Cada um a seu modo, todos transmitiam a angústia e o desespero de serem membros de minoria indígena num país que se fazia de surdo às injustiças étnicas e sociais. Desenvolvi fortes sentimentos de empatia por aqueles índios estóicos e arrojados, e de ira contida contra um passado e um presente implacavelmente cruéis.

Numa determinada ocasião especialmente dramática (a tentativa de suicídio de um desses heróis sem louros), naqueles meses que antecederam à Nova República de 1985, fiquei como que paralisada, sem conseguir refletir produtivamente sobre o que se passava ao meu redor. Depois dessa momentânea paralisia intelectual, comecei a aprender a transformar esses sentimentos em análises antropológicas, nas quais não faltava uma boa dose de impotência cívica. Foi uma paralisia produtiva. Escrevi o artigo "Categorias étnicas do pensamento Sanumá: contrastes intra e interétnicos" (Ramos, 1990, capítulo 10) logo depois de um momento de aguda tomada de consciência (talvez semelhante ao queVirginia Woolf chamou de moments of being) do que deve ser sentir-se "índio" num meio hostil. Apesar do título tão morno, este trabalho é fruto de um mergulho quase metafísico no sofrimento daqueles índios: um, embriagado, resgatado da sarjeta depois de uma briga de bar no fim de um dia perdido nas entranhas do poder em Brasília; outro, imobilizado à força para evitar que se matasse para não levar para casa mais um fracasso político; ainda outro, emocionalmente confuso, temendo pela própria vida se voltasse à sua terra depois de denunciar 
no exterior os poderes locais. Foi então que me dei conta da situação privilegiada dos Sanumá que, naquela época, nem sequer conheciam a palavra índio e menos ainda o conceito de discriminação. Sua inocência interétnica era então quase total.

Daí em diante, acompanhei de perto os desdobramentos do movimento indígena no Brasil e em outros países, dediquei-me a escrever sobre suas várias facetas, o que resultou na publicação de Indigenism (Ramos, 1998) e em vários artigos que aguardam maior atenção editorial. Em suma, o campo do Indigenismo ajudou a aplacar o meu desconforto inicial de ter dedicado meu primeiro grande esforço etnográfico ao que arrisco chamar de "amenidades acadêmicas", ou seja, pesquisar e escrever sobre temas antropológicos na tranquilidade e no conforto de uma situação de campo livre dos sobressaltos e da virulência do contato interétnico descontrolado. Hoje reconheço que aqueles meus melindres eram, na verdade, fruto de um lamentável equívoco que, felizmente, não teve maiores consequências. No fim das contas, até me felicito por ter feito o que fiz. Afinal, sem o mergulho profundo na vida íntima de um povo, o estudo do indigenismo não teria a densidade que só se adquire com a experiência vivida.

A razão de ordem acadêmica que me fez abraçar o indigenismo tem a ver com o desconforto que sempre senti no campo dos estudos etnográficos com seus debates miúdos e, quase sempre, distantes da minha experiência vivida. Ficava perplexa (já não fico mais) com questionamentos do tipo: Será que o que os Sanumá têm são mesmo linhagens? Se ninguém as viu antes por ali é porque não existem, e é Alcida que está errada. Descendência estava out, corpo estava in, de modo que minha análise fora de moda não convenceu ninguém. Aos poucos fui perdendo o interesse pelos floreados acadêmicos feitos de fiapos de compreensão de algum mundo indígena e fui dando cada vez mais valor ao processo de ouvir os próprios índios e fazer deles os solistas e não simplesmente o coro, muitas vezes escondido nos bastidores dos espetáculos etnográficos, quando não passam de meros pretextos para o etnógrafo exibir o seu virtuosismo analítico. Perdi a paciência com debates estéreis sobre detalhes microscópicos de algum sistema de parentesco que, não poucas vezes, é mais o resultado de preocupações teóricas do momento do que da experiência social e do interesse real de alguém de carne e osso.

Além disso, comecei a perceber que estudar povos indígenas não é, afinal, tão diferente do que vemos os brasilianistas fazerem conosco: pode até ser que não estejam errados, mas... estarão certos? Quantas camadas ocultas de significado ficam ao largo da nossa compreensão devido, por exemplo, a limitações linguísticas? Quantas nuances - dessas que fazem um povo ser ele mesmo e não outro - deixamos de captar porque, afinal, somos apenas transeuntes passageiros por aquele mundo? E, o que é pior, a exemplo dos tais brasilianistas, desenvolvemos o mau hábito 
de pontificar sobre eles: “Os Sanumá são ou pensam assim, os Bongo-bongo são ou pensam assado", sem a humildade de dizer "Eu creio que seja assim, segundo minha percepção, parece ser assim”. Cada vez mais consciente das nossas míseras debilidades e convencida de que é preciso mudar esse status quo, venho propondo que, afinal, a etnografia é coisa muito séria para ficar só nas mãos dos etnógrafos acadêmicos (Ramos, 2008).

Proponho, enfim, que deixemos de monopolizar o espaço etnológico e encorajemos os indígenas - como os próprios brasileiros, objeto de estudo dos brasilianistas - a se lançarem na produção de autoetnografias, agora que a educação superior indígena, mesmo ainda precária, está aqui para ficar. Essa educação, que demorou tanto a lhes chegar, muito contribuindo para mantê-los ainda mais aprisionados numa situação de assimetria degradante vis-à-vis à sociedade nacional, é condição sine qua non para que essas autoetnografias se materializem e tomem o caráter de instrumentos políticos na luta interétnica, indo além dos recursos discursivos para seu próprio uso interno, como vemos explicitados na coletânea Pacificando o Branco (Albert \& Ramos, 2000). Neste sentido, não há por que esperar que tais autoetnografias sigam o cânone acadêmico. Com a combinação de educação de qualidade e experiências étnicas diversas, abre-se uma vasta gama de possibilidades.

Vou agora tentar desfiar a terceira razão do que chamo de ordem processual. Assim como Bruno Latour (1994) propõe a aplicação dos conhecimentos etnográficos - adquiridos em escala micro - a fenômenos de grandeza macro, mas não de maneira literal, que acaba caindo em banalidades, eu também me convenci de que o saber antropológico tem a obrigação de se fazer sentir fora do seu nascedouro. Da aldeia à nação, esse saber percorre um caminho que às vezes se cruza com os de outras disciplinas, mas se ele é realmente antropológico, deve permanecer fiel à sua identidade. Trata-se de um processo de ampliação de escala, o que requer adaptações de método, abordagem teórica, forma de expressão escrita e até de vocabulário. A matéria-prima dos dados pode vir de fontes diversas, como a literatura, a história, a política, mas a abordagem continua sendo informada pela perspectiva antropológica.

No meu caso específico, tomei consciência de tudo isso já depois de ter incursionado por esse macro que é a nação brasileira. O fio condutor evidente que me levou ao interesse pela construção da nação foi o campo das relações interétnicas, especificamente, entre índios e brancos. Daí me veio à consciência algo que é tão claro quanto relegado: todas as nações das Américas se construíram sobre os escombros indígenas e, portanto, devem ter sempre um componente ideológico sobre os índios. Em outras palavras, afirmando ou negando o papel dos indígenas na sua formação, todas essas nações expõem as suas forças e fraquezas ao serem 
vistas pelo prisma do indigenismo. É como se os índios ocupassem o inconsciente nacional, algo que as nações se esforçam por esconder, mas que volta e meia vem à tona. Então entendi o óbvio: por que razão o momento fundamental ou o evento fundador (Paul Ricoeur, 1978) para flagrarmos o nascimento de uma nação americana, aquele ponto estratégico em que sua identidade começou a ser efetivamente montada, é o processo de independência do século XIX pelo qual passaram todas as colônias da América Latina. Nesta perspectiva, o principal foco de interesse não são mais os índios em si, mas naquilo em que eles foram transformados pelas nações que se criaram às suas custas, ou seja, o retrato a perseguir não é o do indígena etnográfico, mas o da nova nação americana.

E foi assim que desemboquei no projeto atual de um estudo comparado de construção da nação através do indigenismo, tomando o Brasil e a Argentina como primeiro passo (Ramos, 2009) que deve, mais tarde, abarcar a Colômbia, a Venezuela e talvez outros vizinhos, se houver tempo e interesse. Devo reafirmar que nada disto poderia ser feito se eu não tivesse me equipado com uma bagagem etnográfica como a que adquiri na minha pesquisa com os Sanumá. Mas devo confessar também que as minhas incursões pela militância indigenista deslocaram o meu "momento etnográfico" para uma posição coadjuvante nos meus projetos profissionais. Convenci-me de que há mais entre o céu e a terra do que - perdão pela irreverência - a "vã etnografia”, o gosto por cultivar filigranas analíticas no aconchego da academia.

Minha passagem da etnografia indígena para o indigenismo tem se dado de maneira muito gradual e, a rigor, ainda não terminou. Apesar de tudo, continuo interessada em voltar a temas etnográficos, mas já no contexto das relações dos Sanumá com o mundo abrangente. Por exemplo, seu interesse material e intelectual pelo ouro, deflagrado pela invasão garimpeira dos anos 80 e 90, esse ouro que lhes causou tantos transtornos, mas que lhes deu muito que pensar (Ramos, 1996). Afinal, uma vez etnógrafa, sempre etnógrafa, mesmo que o campo de visão tenha se dilatado desmesuradamente. Como num tear, o movimento de ida e volta entre o micro e o macro tem a vantagem de abrir ou fechar a lente antropológica de modo a enfatizar ora a figura, ora o fundo na busca pela compreensão tanto do detalhe quanto da Gestalt do social. É para alcançar esta compreensão que me servem as teorias antropológicas, e não para transformar a riqueza etnográfica em mera matéria-prima que alimenta a máquina de fazer jogos teóricos muitas vezes mirabolantes ou simplificados receituários que resultam numa uniformização de análises que não condiz com a diversidade cultural vigente. Acessemos as teorias, mas deixemos que elas cumpram o seu papel de guias produtivos a serviço de uma antropologia esclarecida. 
O grupo de pesquisa que coordeno para o $\mathrm{CNPq}$ tem o espaçoso título de Etnologia Indígena e Indigenismo e congrega colegas e estudantes cujas pesquisas parecem falar-se umas às outras, precisamente porque partilham idiomas antropológicos mutuamente inteligíveis. À moda de uma língua franca que nos salva de nos perdermos pelos labirintos da diversidade cultural, as teorias antropológicas têm um papel muito mais nobre do que em geral lhes é atribuído. Sem nunca substituírem a experiência vivida, elas têm a capacidade de nos abrir os sentidos para o inesperado e até o inimaginável. Bem utilizadas, elas podem nos ajudar a transformar perplexidade ou desatenção em estado de alerta para realmente compreendermos a profundidade de afirmações que tantas vezes ouvimos, mas não introjetamos, perdendo a oportunidade de levar ao pé da letra o que os indígenas nos dizem, embora sem grande esperança de serem devidamente entendidos.

Quando os índios nos dizem que os "avós" lhes ensinaram a observar a maneira apropriada de viver, eles se referem a algo que percebemos vaga e abstratamente como tradição, mas que deve ter uma força descomunal, porque só assim se entende a resiliência ${ }^{2}$ com que fazem frente às vicissitudes que os assolam há mais de cinco séculos. A força da tradição transmitida pelos antigos representa uma verdadeira cidadela que só será expugnável com a morte física dos descendentes. Até onde vai a nossa real compreensão desse portento cultural? Quem de nós já levou às últimas consequências as implicações disso que nos é dito com tanta frequência? Vejamos o que nos diz Lorenzo Muelas, o sábio da etnia guambiano na Colômbia que já foi parlamentar constituinte, senador da república e continua sendo o dirigente maior da sua região:

Mas nunca devemos perder de vista que essas leis não são as nossas leis, que as normas às quais nos devemos aferrar com todas as nossas forças são as ditadas por nosso Direito Maior, por essas leis originárias, ancestrais, tão antigas como a criação do mundo, emanadas de nossos deuses, desenvolvidas por nossos antepassados que as passaram a nós para orientar a vida e o desenvolvimento harmônico com a Mãe Terra dos nossos povos há milhares de anos antes da chegada das gentes europeias a nossos territórios (Muelas, 2007).

Como etnógrafos, somos perfeitamente capazes - ou deveríamos ser - de identificar, mapear e até explicar em que consiste esse Direito Maior. No entanto, o que vejo como uma imensa lacuna em nossas análises - talvez uma incontornável limitação para alcançar as camadas mais recônditas de outros mundos semânticos, como Levy-Bruhl ousou sugerir - é chegar a entender a fundo como e quanto aquilo que Muelas designa como "Direito" é responsável pela resiliência dos ín- 
dios, sua capacidade ferrenha de voltar a viver depois de sofrerem tantos golpes da dominação, sobrevivendo a tudo e a todos. Que os indígenas tenham chegado ao século XXI na qualidade de indígenas e que atribuem isto à força de sua cultura não é novidade para nós. Mas fica ainda um resíduo - ou talvez a parte principal - por ser entendido, algo que não sei explicar e sinto quase como uma intuição. Como afirma Niezen, os antropólogos, "por mais sinceros, capazes ou persistentes que sejam nunca são capazes de perscrutar as profundezas de um sistema conceitual alheio" (2003:106). Essa recôndita intimidade cultural, talvez o elemento-chave que distingue um povo de todos os outros, parece ser vedada a quem não lhe pertence.

De que é feita essa convicção inabalável que continua animando e dando sentido às suas lutas étnicas? Que força extraordinária é essa que é capaz de sustentar a firme certeza que têm os povos indígenas de seu próprio valor, resistindo a séculos de pressões em contrário, mesmo quando suas convicções, estremecidas, se retraíam temporariamente? O que há nesse aparato conceitual, rotulado por Muelas como "Direito Maior", que lhes dá a garantia do viver correto, por mais que tenham sido bombardeados pelas renitentes imposições ocidentais? Entrar no âmago de questões como estas é pôr diante da antropologia o desafio de enveredar por caminhos pouco iluminados pelo facho de luz das suas teorias correntes. É também, como adianta Stuart Kirsch (2006), uma possibilidade de trazer à tona, de tornar visíveis, como quem revela uma fotografia, as teorias indígenas como legítimas epistemologias par a par com seus congêneres acadêmicos. Não submergi-las sob a onda das nossas ideias recebidas, por mais "científicas" que nos pareçam, por mais poderosa que seja a última moda, é a maneira mais segura de evitar a armadilha da sobreteorização que acaba por reduzi-las a meros (pre)textos. Reconhecer que as teorias nativas podem nos levar mais longe e mais fundo do que as nossas rumo à compreensão de determinado mundo indígena é um exercício tanto de sabedoria antropológica quanto de humildade científica, sem a qual a almejada superação de nossas limitações de conhecimento fica seriamente comprometida. Quero crer que só poderemos chegar à possibilidade de um diálogo franco e produtivo com os sujeitos das nossas etnografias, e assim elevar o patamar da intercomunicabilidade, quando aprendermos a não reduzir suas teorias às nossas, mas tomar ambas como vozes com iguais decibéis que se falam mutuamente.

Sonhar pode ser o primeiro passo para consumar. 


\section{Notas}

*. Esta é uma versão ampliada do texto apresentado na seção "Conversa com o Autor", $26^{\text {a }}$ Reunião da ABA, Porto Seguro, 03 de junho de 2008. Agradeço a Myriam Jimeno e a Wilson Trajano Filho por seus comentários e críticas.

1. Bildung, conceito do humanismo alemão que se refere à formação de uma pessoa, com ênfase na sua formação profissional (Gadamer, 1975:10-19).

2. Resiliência, conceito original da física, refere-se à capacidade de um corpo que sofre golpe ou tensão de recuperar seu estado normal quando for suspenso o "estado de risco". 


\section{Referências bibliográficas}

ALBERT, Bruce \& RAMOS, Alcida Rita (orgs.). 2000. Pacificando o branco: Cosmologias do contato no norte-amazônico. São Paulo: Editora Unesp/Imprensa Oficial SP/IRD.

GADAMER, Hans-Georg. 1975. Truth and method. Nova York: Crossroad.

KIRSCH, Stuart. 2006. Reverse Anthropology: Indigenous analysis of social and environmental relations in New Guinea. Stanford: Stanford University Press.

LATOUR, Bruno. 1994. Jamais fomos modernos. Rio de Janeiro: Editora 34.

MUELAS, Lorenzo. 2007. Los pueblos indígenas y la Constitución de Colombia: Primera experiencia de participación indígena en los procesos constituyentes de América Latina. Trabalho apresentado no Simpósio Constituições Nacionais e Povos Indígenas, Universidade de Brasília, 9 a 11 de maio.

NIEZEN, Ronald. 2003. The origins of indigenism: Human rights and the politics of identity. Berkeley: University of California Press.

RAMOS, Alcida Rita. 1980. Hierarquia e simbiose: Relações intertribais no Brasil. São Paulo: Hucitec/INL-MEC.

1990. Memórias sanumá: Espaço e tempo em uma sociedade yanomami. São Paulo: Marco Zero/Brasília: Edunb.

. 1996. “A profecia de um boato: Matando por ouro na área Yanomami”. Anuário Antropológico, 95:121-150.

. 1998. Indigenism: Ethnic politics in Brazil. Madison: University of Wisconsin Press.

. 2008. Disengaging anthropology. In: Deborah Poole (org.). A companion to Latin American anthropology. Oxford: Blackwell. pp. 466-484.

2009. "O indigenismo na montagem da nação: Contrastes e convergências entre Brasil e Argentina”. Anuário Antropológico / 2007 (no prelo). 
RICOEUR, Paul. 1978. O conflito das interpretações. Rio de Janeiro: Imago.

TROUILLOT, Michel-Rolph. 1991. "Anthropology and the savage slot:The poetics and politics of otherness”. In: Richard G. Fox (org.). Recapturing anthropology:Working in the present. Santa Fé, Novo México: School of American Research Press. pp. 17-44. 


\section{Resumo:}

Relato da trajetória profissional de Alcida Rita Ramos desde suas primeiras incursões na antropologia como aluna do Professor Roberto Cardoso de Oliveira no Museu Nacional, passando pela pós-graduação na Universidade de Wisconsin, Madison, até a sua aposentadoria na Universidade de Brasília, com ênfase nas pesquisas entre os Sanumá, subgrupo Yanomami e, posteriormente, no indigenismo comparado na América Latina.

\section{Palavras-chave:}

Biografia, Alcida Rita Ramos, etnografia, indigenismo.

\section{Abstract:}

Alcida Rita Ramos describes her professional trajectory from her first steps as an anthropology student of Professor Roberto Cardoso de Oliveira at the National Museum in Rio de Janeiro through her graduate studies at the University of Wisconsin, Madison, up until her retirement at the University of Brasília. She emphasizes her research work among the Sanumá, a Yanomami subgroup in north Brazil and, more recently, on comparative indigenism in Latin American.

\section{Key words:}

Biography,Alcida Rita Ramos, ethnography, indigenism. 